\title{
Features of the growth of austenite grains in steel forged from a large ingot
}

\author{
V. I. Bogdanov ${ }^{1}$ I. V. Teplukhina ${ }^{1}$, A. S. Tsvetkov ${ }^{\dagger, 1,2}$, T. I. Titova ${ }^{3}$, \\ N.A. Shulgan ${ }^{3}$ L. A. Milyakova ${ }^{3}$ \\ †a.s.tsvetkow@gmail.com \\ ${ }^{1}$ NRC “Kurchatov institute” - CRISM “Prometey”, 49 Shpalernaya St., St. Petersburg, 191015, Russia \\ ${ }^{2}$ Peter the Great Saint Petersburg Polytechnic University, 29 Polytehnicheskaya St., St. Petersburg, 195251, Russia \\ ${ }^{3}$ TK «OMZ - Izhora», Izhorskiy Zavod, w/o No., St. Petersburg, 196650, Russia
}

For the production of large-sized equipment of nuclear power plants heat-resistant $\mathrm{Cr}-\mathrm{Mo}-\mathrm{V}$ and $\mathrm{Cr}-\mathrm{Ni}-\mathrm{Mo}-\mathrm{V}$ steel ingots weighing $360 \div 420$ tons are used. One of the important characteristics of forgings, obtained from such large ingots, is the size of austenite grains, which has a significant impact on mechanical properties. Improving the reliability of the equipment of nuclear power reactors is possible by increasing the thickness of the wall of the reactor vessel, as well as by ensuring the quality of the forged metal made from the large ingot and the homogeneity of the metal structure and properties. In this work, the kinetics of growth of austenitic grains is studied under different temperature and time regimes of isothermal aging. The grain size was measured on the forging metal with a wall thickness during heat treatment up to $650 \mathrm{~mm}$, made of 15H3NMFA-A reactor structural steel. The studied parts were slightly different in chemical composition - the top and bottom parts of the ingot weighing 360 tons. The study was conducted by the method of quantitative metallography and showed the difference in the kinetics of grain growth in different parts of the forging from a large ingot. The latter is explained by the fact that, due to the peculiarities of the method and technology of smelting, as well as a significant mass, the processes of liquation in large ingots are highly developed. The growth curves of austenitic grains were constructed for top and bottom parts, depending on the temperature and time parameters of the heat treatment regimes. The results show the presence of a certain difference in the tendency of austenitic grains growth in different zones of the studied forging, which can affect on the homogeneity of the metal structure and properties.

Keywords: large ingot, steel, austenite, bainite, grain growth kinetics.

УДК: 620.186.8:620.183.24

\section{Особенности роста зерен аустенита в металле поковки из крупного слитка конструкционной стали}

\author{
Богданов В. И. ${ }^{1}$ Теплухина И. В. ${ }^{1}$, Цветков А. С. ${ }^{\dagger, 1,2}$, Титова Т. И. ${ }^{3}$, \\ Шульган Н. А. ${ }^{3}$, Милякова Л. А. ${ }^{3}$ \\ ${ }^{1}$ НИЦ «Курчатовский институт» - ЦНИИ КМ «Прометей», ул. Шпалерная 49, С.-Петербург, 191015, Россия \\ ${ }^{2}$ Санкт-Петербургский политехнический университет Петра Великого, ул. Политехническая 29, \\ С.-Петербург, 195251, Россия \\ ${ }^{3}$ ТК «ОМЗ-Ижора», Ижорский завод, б/н, С.-Петербург, 196650, Россия
}

Для изготовления крупногабаритного оборудования атомных энергетических установок используются слитки из теплоустойчивых сталей $\mathrm{Cr}-\mathrm{Mo}-\mathrm{V}$ и $\mathrm{Cr}-\mathrm{Ni}-\mathrm{Mo}-\mathrm{V}$ композиции легирования массой $360 \div 420$ т. Одной из важных характеристик металла заготовок, получаемых из таких сверхкрупных слитков, является размер аустенитного зерна, оказывающий значительное влияние на механические свойства. Повышение надежности оборудования атомных энергетических реакторов возможно за счет увеличения толщины стенки корпуса реактора, обеспечения металлургического качества поковок, выполненных из крупных слитков, а также однородности структуры металла и свойств заготовок. В данной работе на металле опытной поковки (цилиндрической обечайки) из стали марки 15ХЗНМФА-А с толщиной стенки под термическую обработку 650 мм, изготовленной из слитка массой 360 т, 
проведено исследование кинетики роста аустенитных зерен при различных температурных и временных параметрах изотермической выдержки. Исследование, проведенное методом количественной металлографии, показало различие в кинетике роста зерна в различных частях поковки, несколько отличающихся по химическому составу. Последнее объясняется тем, что ввиду особенностей способа и технологии выплавки, а также значительной массы, процессы ликвации в крупных слитках получают заметное развитие. Построены кривые роста аустенитных зерен для прибыльной и донной частей поковки в зависимости от температурно-временных параметров термической обработки. Изложенные результаты показывают наличие определенной разницы в склонности к росту аустенитного зерна в различных зонах исследованной поковки, что может отразиться на степени однородности структуры и механических свойств.

Ключевые слова: крупный слиток, сталь, аустенит, бейнит, кинетика роста зерна.

\section{1. Введение}

Для изготовления крупногабаритного оборудования энергетических установок используются слитки из теплоустойчивых сталей $\mathrm{Cr}-\mathrm{Mo}-\mathrm{V}$ и $\mathrm{Cr}-\mathrm{Ni}-\mathrm{Mo}-\mathrm{V}$ композиции легирования массой $360 \div 420$ т. Одной из важных характеристик металла заготовок, получаемых из таких сверхкрупных слитков, являются размер аустенитного зерна, оказывающего значительное влияние на механические свойства. Укрупнение аустенитных зерен в большинстве случаев приводит к ухудшению свойств, сказываясь, в первую очередь, на величине ударной вязкости и критической температуре хрупкости $[1,2]$, а также на таких её характеристиках, как чувствительность к отпускной и тепловой хрупкости $[3,4]$. С этой точки зрения интерес представляет склонность аустенитных зерен к росту в процессе нагрева при технологических операциях пластической и термической обработки.

Основным фактором, определяющим склонность к росту зерен аустенита в стали, является её химический состав. Почти все легирующие элементы, за исключением $\mathrm{Mn}$, тормозят рост зерна. Наиболее эффективными в этом отношении являются $\mathrm{Ti}, \mathrm{Al}, \mathrm{Nb}, \mathrm{V}$ и $\mathrm{Zr}$, несколько менее сильно действуют Мо и $\mathrm{Cr}[5,6]$. Влияние легирующих элементов в этом отношении связывают с барьерным эффектом, определяемым наличием на границах зерен труднорастворимых частиц карбидов, нитридов и оксидов. Другой вероятной причиной является изменение этими элементами параметров диффузии и самодиффузии по границам зерен [7]. С этой точки зрения должны способствовать укрупнению зерен $\mathrm{Ni}, \mathrm{Si}, \mathrm{P}$, а также, в случае его присутствия в твердом растворе аустенита, Al, которые понижают прочность атомной связи в решетке $\gamma$-Fe. Повышение содержания С и $\mathrm{N}$ в твердом растворе также способствует росту зерен, тогда как наличие карбидов и нитридов на границах тормозит рост аустенитных зерен.

Из практики хорошо известно, что сталь одной марки разных плавок может существенно различаться по склонности к росту аустенитных зерен вследствие колебаний химического состава, особенностей способа и технологии выплавки, а также технологии пластической и термической обработки. Значительные флуктуации химического состава, связанные с развитием ликвационных процессов при кристаллизации металла, могут наблюдаться и внутри одного слитка, особенно при большой его массе $[8,9]$. Химическая неоднородность в особо крупных слитках может быть связана также с тем, что такие слитки в ряде случаев отливаются из металла нескольких плавок, изготовленных в различных сталеплавильных агрегатах [10-12]. В связи с этим, можно сказать, что в металле разных зон крупного слитка будет проявляться, в той или иной степени, и различная склонность к росту аустенитных зерен при нагреве, а развитие значительной дендритной ликвации может способствовать образованию разнозернистой структуры металла. Дендритная неоднородность, наследуемая от слитка, приводит к структурной неоднородности, чему также способствует различие в скорости нагрева и охлаждения поверхностного и центрального слоев поковки. Отмеченные обстоятельства, наряду с особенностями технологии пластической обработки, могут непосредственно отразиться на степени однородности структуры и механических свойств стали.

В данной работе исследована кинетика роста зерен аустенита и сравнительная склонность к их росту в металле прибыльной и донной частей крупной поковки типа обечайки, откованной из опытного слитка массой 360 т стали марки 15Х3НМФА-А.

\section{2. Материал для исследования и методика испытаний}

Технология получения крупного слитка реакторной стали предусматривает последовательную заливку в изложницу металла, выплавленного на особо чистой по содержанию вредных примесей шихте, с содержанием углерода в металле, уменьшающимся от прибыльной части слитка к донной, а также применение обработки металла на установке внепечного рафинирования и вакуумирования и разливку в вакууме. Химический состав исследованного металла по основным элементам приведен в Табл. 1.

Металлографическое исследование металла от донной и прибыльной частей поковки из средней трети сечения (толщина стенки 650 мм) выполнено при увеличении $\times 100$ и $\times 500$ на оптическом микроскопе Techno Meiji IM 7200 с применением программного обеспечения для анализа изображений Thixomet Pro. Травление проводили в 5\% растворе азотной кислоты.

Кинетику роста аустенитного зерна изучали методом высокотемпературной и количественной металлографии [13-16]. На испытательной машине 
ИМАШ-20-75 «Ала-Тоо» образцы нагревали в вакууме при 880, 920 и $960^{\circ} \mathrm{C}$ с выдержками 1, 3 и 5 часов (эксперимент при температуре $920^{\circ} \mathrm{C}$ проводился только на металле от донного конца поковки). В результате вакуумного травления на поверхности выявлялись границы действительных аустенитных зерен, которые изменяли свои размеры и форму в зависимости от температурно-временных параметров термической обработки. По полученным фотографиям (c увеличением $\times 100)$ проводили количественный анализ зеренной структуры металла методом случайной секущей с последующим построением и анализом зависимости распределения величин хорд по размерам (по $5 \div 6$ размерных групп из выборок по $100 \div 150$ хорд) от температуры и времени нагрева. Среднюю величину хорды рассчитывали по формуле:

$$
H_{\text {average }}=\frac{1}{N} \sum^{n} H_{i} \times i
$$

где $H_{\text {average }}-$ средняя величина хорды; $i-$ количество групп разбивки; $H_{i}-$ средний размер хорды в группе; $\mathrm{N}$ - общее количество хорд.

\section{3. Результаты исследований и их обсуждение}

Из данных Табл. 1 видно, что металл со стороны прибыльного и донного концов поковки различается, в основном, по содержанию углерода, при практически одинаковом содержании других элементов. Эта разница в химическом составе проявляется в положении критических точек для металла донного конца поковки по сравнению с прибыльным.

На основании исследований металла донной и прибыльной частей поковки по методике, изложенной в [17], для донного конца поковки значение $A_{\mathrm{C} 1}$ равно $770^{\circ} \mathrm{C}$, для прибыльного отмечено повышение значения точки $A_{\mathrm{C} 1}$ на $20^{\circ} \mathrm{C}$, а также понижение точек начала и окончания бейнитного превращения относительно значений для донного конца $\left(5_{\text {н }}-560^{\circ} \mathrm{C}\right.$ и $\left.Б_{\text {к }}-340^{\circ} \mathrm{C}\right)$ на 50 и $30^{\circ} \mathrm{C}$. Точка $A_{\text {Сз }}$ для металла от обоих концов поковки при этом одинакова.

В исходном состоянии - после термообработки по режиму двойной закалки от температур 960 и $920^{\circ} \mathrm{C}$ и отпуска при $660^{\circ} \mathrm{C}$ - металл донного и прибыльного концов поковки имел типичную структуру продуктов распада мартенсита и бейнита различной степени дисперсности с размером зерна G3-G4 по шкале ГОСТ 5639 (Рис. 1).

Кинетику роста аустенитного зерна изучали по выявившейся в результате вакуумного травления микроструктуре на образцах, вырезанных из донной и прибыльной частей поковки, после выдержки в течение 1,3 и 5 часов при температурах 880, 920 и $960^{\circ} \mathrm{C}$. На Рис. 2 представлена структура после выдержки в течение 5 часов при всех исследованных температурах.

Количественный анализ зеренной структуры металла представлен на Рис. 3, 4. На данных рисунках соединены средние точки размерных классов гистограмм, причем значения ординат этих точек показывают относительную частоту попадания хорд определенного размерного класса в анализируемой выборке. Полученные результаты позволили выявить существенные различия в поведении металла прибыльной и донной частей поковки в зависимости от температурно-временных параметров режима термической обработки.

При выдержке в течение 1 ч при $880^{\circ} \mathrm{C}$ границы зерен в металле донной части не выявлялись (Рис. 3 a). После 3-часовой выдержки при этой температуре выявляется однородная мелкозернистая структура. При увеличении времени выдержки эта структура укрупняется, главным

Табл. 1. Химический состав металла поковки, мас.\%.

Table 1. Chemical composition of forging metal, wt.\%.

\begin{tabular}{|c|c|c|c|c|c|c|c|c|c|c|}
\hline $\begin{array}{c}\text { Metal sampling area } \\
\text { Место отбора проб }\end{array}$ & $\mathrm{C}$ & $\mathrm{Si}$ & $\mathrm{Mn}$ & $\mathrm{S}$ & $\mathrm{P}$ & $\mathrm{Cr}$ & $\mathrm{Ni}$ & $\mathrm{Mo}$ & $\mathrm{Cu}$ & $\mathrm{V}$ \\
\hline $\begin{array}{c}\text { Forging - top } \\
\text { Прибыльный конец поковки }\end{array}$ & 0.18 & 0.31 & 0.38 & 0.005 & 0.006 & 2.56 & 1.07 & 0.65 & 0.06 & 0.11 \\
\hline $\begin{array}{c}\text { Forging - bottom } \\
\text { Донный конец поковки }\end{array}$ & 0.12 & 0.28 & 0.34 & 0.003 & 0.006 & 2.44 & 1.04 & 0.63 & 0.07 & 0.10 \\
\hline
\end{tabular}

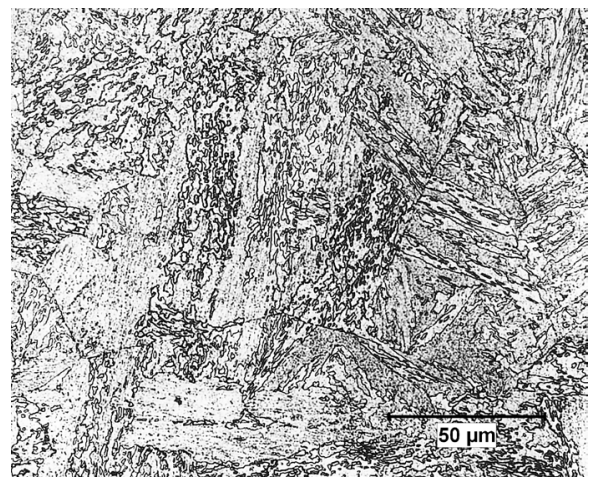

a

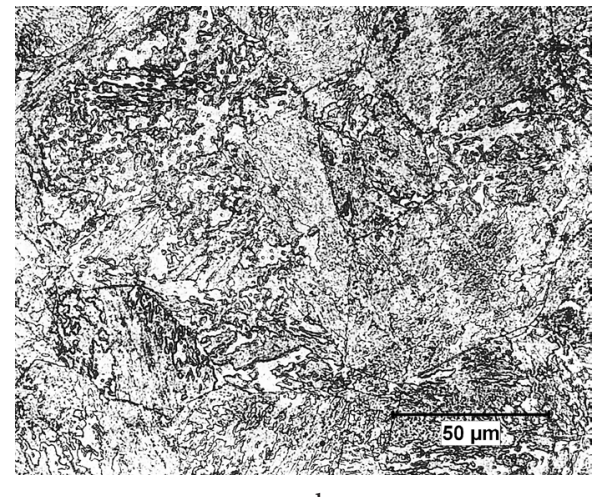

$\mathrm{b}$

Рис. 1. Типичная микроструктура прибыльной (a) и донной (b) частей поковки (×500).

Fig. 1. Typical microstructure of top (a) and bottom (b) forging parts $(\times 500)$. 


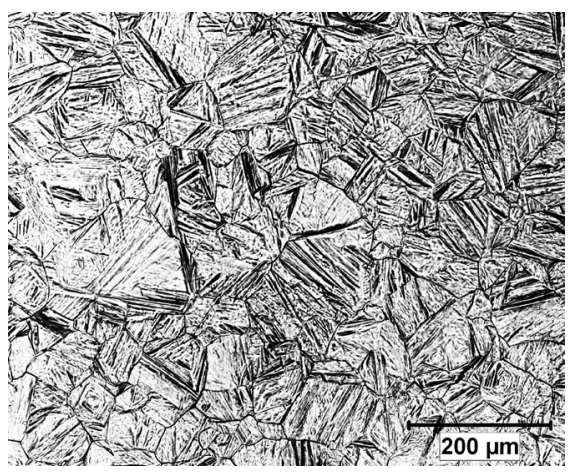

a

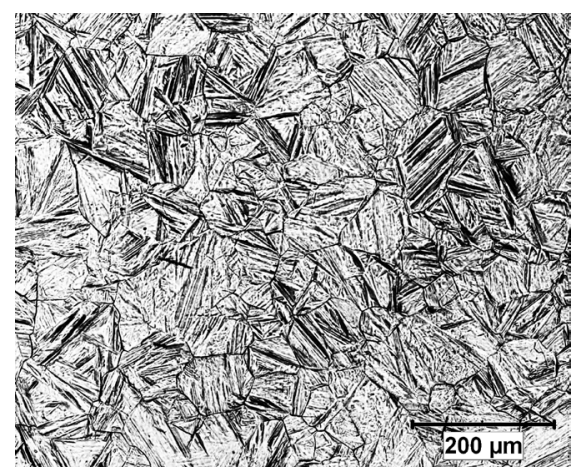

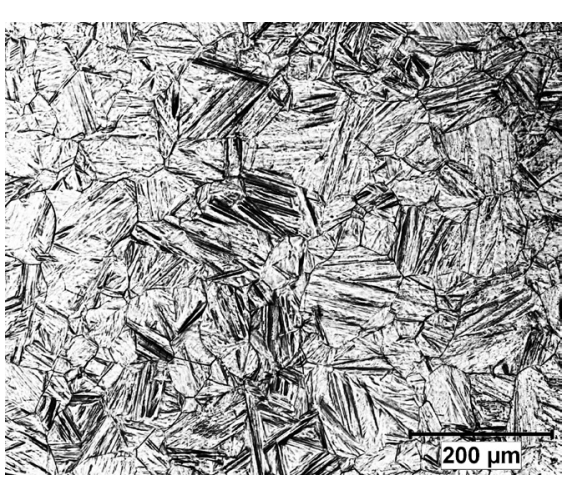

d

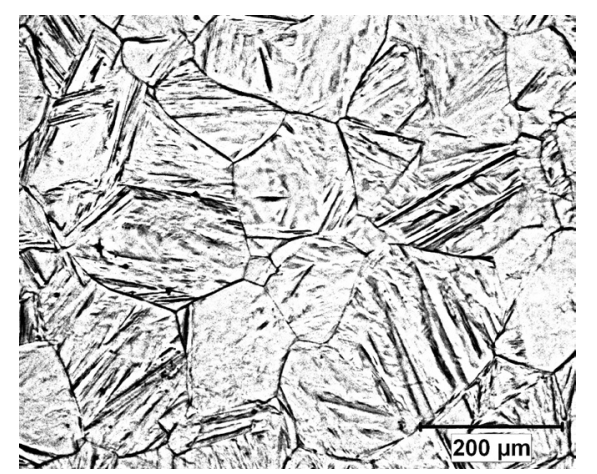

b

Рис. 2. Микроструктура прибыльного $\left(880^{\circ} \mathrm{C}-5\right.$ часов (a), $960^{\circ} \mathrm{C}-5$ часов (b)); и донного $\left(880^{\circ} \mathrm{C}-5\right.$ часов (c), $920^{\circ} \mathrm{C}-5$ часов $(\mathrm{d})$, $960^{\circ} \mathrm{C}-5$ часов (e)) конца поковки после вакуумного травления $(\times 100)$.

Fig. 2. Microstructure of top $\left(880^{\circ} \mathrm{C}-5\right.$ hours (a), $960^{\circ} \mathrm{C}-5$ hours (b)); and bottom $\left(880^{\circ} \mathrm{C}-5\right.$ hours $(\mathrm{c}), 920^{\circ} \mathrm{C}-5$ hours $(\mathrm{d})$, $960^{\circ} \mathrm{C}-5$ hours $\left.(\mathrm{e})\right)$ parts of forging after vacuum etching $(\times 100)$.

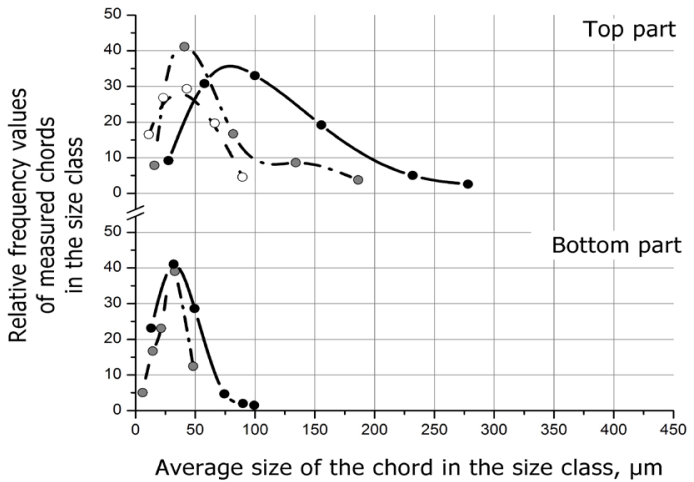

a

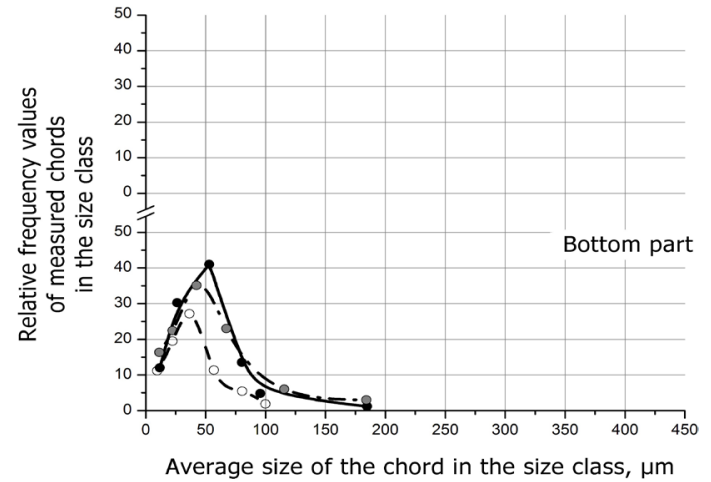

$\mathrm{b}$

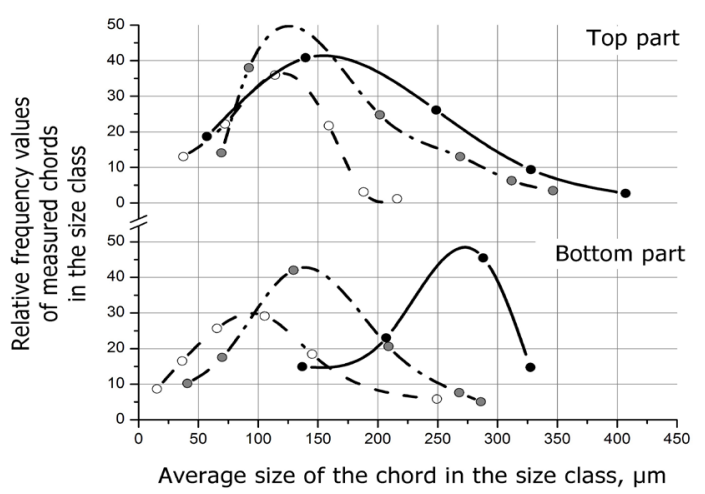

C

Рис. 3. Распределение размеров аустенитных зерен в зависимости от температуры $\left(880^{\circ} \mathrm{C}(\mathrm{a}), 920^{\circ} \mathrm{C}(\mathrm{b}), 960^{\circ} \mathrm{C}(\mathrm{c})\right)$ и длительности изотермических выдержек ( -1 час, $\bullet-3$ часа, $\bullet-5$ часов).

Fig. 3. The size distribution of austenite grains depending on the temperature $\left(880^{\circ} \mathrm{C} \mathrm{(a),} 920^{\circ} \mathrm{C}(\mathrm{b}), 960^{\circ} \mathrm{C}(\mathrm{c})\right)$ and duration of isothermal exposures ( $0-1$ hour, $\bullet-3$ hours, $\bullet-5$ hours). 


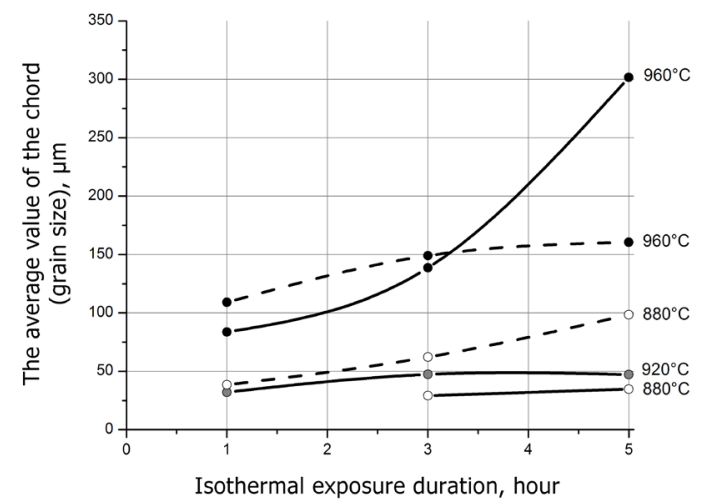

Рис. 4. Зависимость среднего размера зерна аустенита $H_{\text {average }}$ от температуры и времени изотермической выдержки (-- прибыльный конец, - донный конец).

Fig. 4. Dependence of the average grain size of austenite $H_{\text {average }}$ on temperature and time of isothermal exposure (-- top part, - bottom part).

образом, за счет объединения групп мелких зерен в более крупные с образованием новой сетки границ.

В отличие от этого, в металле прибыльной части поковки границы мелких исходных зерен аустенита при температуре $880^{\circ} \mathrm{C}$ выявляются быстрее, в отдельных участках происходит и их объединение, приводящее К возникновению выраженной разнозернистости структуры уже после сравнительно непродолжительных выдержек, причем степень разнозернистости, оцениваемой по размаху распределения, значительно возрастает с увеличением времени нахождения металла при этой температуре (Рис. 3 a).

Следует отметить, что при $880^{\circ} \mathrm{C}$ в металле прибыльной части поковки рост зерна и развитие разнозернистости, равно как и увеличение среднего размера аустенитного зерна, происходит значительно интенсивнее, чем в металле донной части даже при температуре $920^{\circ} \mathrm{C}$ (Рис. 3 b).

Повышение температуры нагрева до $960^{\circ} \mathrm{C}$ приводит к значительному укрупнению зерна, которое возрастает с увеличением времени выдержки (Рис. 4). Разнозернистость в металле донной части не слишком велика и при длительных выдержках относительно меньше, чем в металле прибыльного конца поковки. Механизм роста аустенитных зерен в металле донной части при $960^{\circ} \mathrm{C}$, получающий развитие особенно при длительных выдержках, заключается в миграции границ объединившихся ранее зерен. После 5-часовой выдержки этот процесс приводит к образованию равновесной полиэдрической структуры крупных зерен.

Наибольшая средняя величина зерна составляет, как видно из Рис. 4, около 300 мкм, что соответствует G0 по шкале ГОСТ 5639. В металле прибыльной части поковки процесс объединения групп зерен, имевший место при $880^{\circ} \mathrm{C}$, при нагреве $960^{\circ} \mathrm{C}$ продолжается, а процесс укрупнения зерна по механизму миграции границ зерен не получает существенного развития. Даже после выдержки 5 ч при $960^{\circ} \mathrm{C}$ структура металла прибыльной части не приобретает устойчивой полиэдрической формы - преобладают зерна неправильной формы, причем разнозернистость значительно больше, чем в металле донной части (максимальный размер хорды превышает 400 мкм, что соответствует величине зерна от G0 до G-1 ГОСТ 5639). Средний размер зерен при этом возрастает незначительно (Рис. 4). По-видимому, получающаяся при этом структура не достигает равновесного состояния, и при возрастании значений температурно-временных параметров термической обработки процессы изменения зеренной структуры получат дальнейшее развитие.

Таким образом, в металле донного конца поковки наблюдается относительно слабое увеличение размеров исходных аустенитных зерен вплоть до 3-часовой выдержки при $960^{\circ} \mathrm{C}$ и дальнейший бурный рост зерен с сохранением небольшой разнозернистости. Напротив, для металла прибыльной зоны характерен изначальный неравномерный рост зерна, мало зависящий от возрастания температурно-временных параметров нагрева.

Отмеченные различия в поведении металла прибыльной и донной частей исследованной поковки могут быть связаны, по-видимому, с различием в количестве, размерах и распределении карбидных включений в структуре металла вследствие различий в химическом составе между прибыльной и донной частью. Можно полагать, что в металле прибыльной части с более высоким содержанием углерода имеется большее количество карбидной фазы. При этом включения карбидов крупнее и менее равномерно распределены, чем в металле донной части поковки. Вследствие этого, при температуре $960^{\circ} \mathrm{C}$ и выдержке до 5 часов, карбидные частицы, располагающиеся по границам зерен, растворяются не полностью и сохраняют роль барьеров, препятствующих миграции границ и интенсивному росту зерна аустенита. Однако частичное растворение карбидной фазы способствует образованию разнозернистости в стали. В донной части поковки меньшее содержание углерода способствует образованию мелкодисперсных карбидов после отпуска. Более мелкие и относительно однородно распределенные в металле донной части поковки включения карбидов являются достаточно эффективными препятствиями для движения границ, однако более легко растворяются при повышении температуры нагрева, о чем свидетельствует интенсивный рост зерна после 3-часовой выдержки при $960^{\circ} \mathrm{C}$.

\section{4. Заключение}

Представленные результаты исследований показывают наличие определенной разницы в склонности к росту аустенитного зерна в различных зонах исследованной поковки. Однако разница существенно проявляется только при температурах, более высоких, чем температура «штатного» режима нагрева под закалку заготовок из стали 15ХЗНМФА-А, которая равна $920^{\circ} \mathrm{C}$. Вследствие этого, различия в склонности к росту аустенитных зерен при проведении термической обработки с соблюдением регламентированных режимов нагрева не должны приводить к значительной разнице между различными зонами поковки в отношении размеров исходного аустенитного зерна. 


\section{Литература/References}

1. I. V. Teplukhina, I. I. Grekova, V. V. Dyukov, I. G. Savelieva. Voprosy Materialovedeniya. 2 (50), 19 (2007). (in Russian) [И. В. Теплухина, И. И. Грекова, В.В. Дюков, И. Г. Савельева. Вопросы материаловедения. 2 (50), 19 (2007).]

2. I.V. Teplukhina, A.S. Tcvetkov, O.Y. Zaytseva. Technologiya Metallov. 3, 17 (2016). (in Russian) [И.В. Теплухина, А.С. Цветков, О.Ю. Зайцева. Технология металлов. 3, 17 (2016).]

3. N.T. Tihonova, O.A. Sofrygina, S. Yu. Zhukova, I. Yu. Pyshmintsev, S.M. Bitjukov. Izvestia. Ferrous metallurgy. 5, 60 (2012). (in Russian) [Н. Т. Тихонцева, О.А. Софрыгина, С. Ю. Жукова, И.Ю. Пышминцев, С.М. Битюков. Известия ВУЗ. Черная металлургия. 5, 60 (2012).]

4. T. I. Titova, I. F. Semernina, N. A. Shul'gan, L. A. Milyakova. Tyazheloye mashinostroyeniye. 6, 14 (2012). (in Russian) [Т.И. Титова, И.Ф. Семернина, Н.А. Шульган, Л.А. Милякова. Тяжелое машиностроение. 6, 14 (2012).]

5. V.S. Mes'kin. Osnovy legirovaniya stali. Moscow, Metallurgiya (1964) 684 p. (in Russian) [В. С. Меськин. Основы легирования стали. Москва, Металлургия (1964) 684 c.]

6. E. Gudremon. Spetsial'nyye stali. Moscow, Metallurgiya (1959) 952 p. (in Russian) [Э. Гудремон. Специальные стали. Москва, Металлургия (1959) 952 с.]

7. B.S. Bokstein. Diffuziya v metallakh. Moscow, Metallurgiya (1978) 248 p. (in Russian) [Б. С. Бокштейн. Диффузия в металлах. Москва, Металлургия (1978) 248 c.]

8. V.S. Dub, A. N. Romashkin, A. N. Mal'ginov, I. A. Ivanov, D.S. Tolstykh. Metallurg. 11, 45 (2013). (in Russian)
[В.С. Дуб, А.Н. Ромашкин, А.Н. Мальгинов, И. А. Иванов, Д. С. Толстых. Металлург. 11, 45 (2013).]

9. V.S. Dub, A. N. Romashkin, I. A. Ivanov, D.S. Tolstykh, A. N. Mal'ginov. Metallurg. 12, $44-49$ (2013). (in Russian) [В.С. Дуб, А.Н. Ромашкин, И. А. Иванов, Д.С. Толстых, А.Н. Мальгинов. Металлург. 12, $44(2013)$.]

10. S.K. Scoblo, E.A. Kazachkov. Slitki dlya krupnykh pokovok. Moscow, Metallurgiya (1973) 247 p. (in Russian) [C. К. Скобло, Е.А. Казачков. Слитки для крупных поковок. Москва, Металлургия (1973) 247 с.]

11. S. Kawaguchi, H. Tsukada, K. Suzuki, I. Sat, S. Onodera. Steel Forgings. STP 903. West Conshohocken, PA, ASTM International (1986) p. $398-409$. Crossref https://doi. org/10.1520/STP903-EB

12. B. I. Berezhko, A.G. Ignatenko, Yu.V. Sergeev. Progressivnyye materialy i tekhnologii. 3, 30 (1999). (in Russian) [Б. И. Бережко, А. Г. Игнатенко, Ю. В. Сергеев. Прогрессивные материалы и технологии. 3, 30 (1999).]

13. C. Garci’a de Andre's, F.G. Caballero, C. Capdevila, D. San Martin. Materials Characterization. 49, 121 (2003). Crossref

14. C. Garci’a de Andre's, M.J. Bartolome, C. Capdevila. Materials Characterization. 46, 389 (2001). Crossref

15. T.V. Soshina, A. A. Zisman, E.I. Hlusova. Metallurg. 2, 63 (2013). (in Russian) [T.В. Сошина, А.А. Зисман, Е. И. Хлусова. Металлург. 2, 63 (2013).]

16. M.G. Lozinskiy. Teplovaya mikroskopiya materialov. Moscow, Metallurgiya (1976) 304 p. (in Russian) [М. Г. Лозинский. Тепловая микроскопия материалов. Москва, Металлургия (1976) 304 с.]

17. I. V. Teplukhina, V.M. Golod, A.S. Tsvetkov. Letters on materials. 1 (29), 37 (2018). (in Russian) [И. В. Теплухина, В.М. Голод, А.С. Цветков. Письма о материалах. 1 (29), 37 (2018).] Crossref 